\title{
CLASSES SOCIAIS, MOVIMENTOS SOCIAIS E CIDADANIA: VELHOS PARADIGMAS, NOVAS PERSPECTIVAS
}

Ângela Cristina Belém Mascarenhas

\begin{abstract}
Nenhuma categoria histórica foi mais incompreendida,' atormentada, transfixiada e deshistorizada do que a categoria de classe social; uma formação histórica autodefinidora, que homens e mulheres elaboram a partir de sua própria experiência de luta, foi reduzida a uma categoria estática, ou a um efeito de uma estrutura' ulterior, das quais os homens não são os autores, mas os vetores.
\end{abstract}

E. P. Thompson

\section{RESUMO}

este artigo discute sobre o conceito de classes sociais em sua relação com as questões da cidadania e dos movimentos sociais. 
Palavras chaves: movimentos sociais, classes sociais, velhos paradigmas.

\section{ABSTRACT}

this paper discusses about the concept of social class in relation to the questions of citizenship and social movement.

Mais uma vez recorro a citação de Tompson para iniciar uma discussão sobre a questão do conceito de classes sociais, sem dúvida uma categoria teórica das mais "atormentada" no âmbito da análise sociológica. Atualmente, então, quando os muros caíram, a guerra fria esvazia-se como estratégia de luta pelo domínio político-ideológico e o socialismo é visto como peça de museu, a tendência a conceber os fatos sociais fora da esfera de delineamento do conceito de classes sociais é muito sedutora. Esta categoria é esvaziada de seu potencial explicativo da realidade social. A problemática da desigualdade social sempre tão presente na configuração do mundo moderno, tem sido ultimamente abordada muito em função de elementos tais como: a miséria, a fome, pobreza e direitos de cidadania. O que se pode constatar é que todos estes elementos inseridos em uma análise sistematizada da realidade social não prescindem da composição do conceito de classes sociais para não repercutirem em uma compreensão ôca, desprovida de significado e embasamento. A noção de classes indica a real perspectiva da desigualdade social evitando que a questão repercuta na concepção do "fracasso 
individual", "privado", perdendo a perspectiva do nível coletivo. É claro que o conceito precisa ser capaz de lidar com os dinamismo da realidade, sem se deixar fossilizar ou repercutir em uma camisa de força. Nesse sentido acredito que o estabelecimento de um elo de ligação entre este e a constituição dos movimentos sociais é fundamental.

\section{Classes sociais e movimentos sociais}

Segundo Tompson (1981), "as classes surgem porque homens e mulheres, em relações produtivas determinadas, identificam seus interesses antagônicos e passam a lutar, a pensar e a valorar em termos de classes: assim o processo de formação de classes é um produto de auto-confecção, embora sob condições dadas". Ele nos oferece uma concepção do momento de configuração de uma classe social, onde estrutura e sujeito mantêm uma relação de não superposição. A classe acontece, então, enquanto as pessoas vivem sua própria história, configurando-se como uma formação econômica, política, social e cultural. A classe não existe independente da elaboração de uma representação de classe - da criação de um mundo de significação, em que as necessidades e interesses dos sujeitos são tratados em sua cultura e consciência. Desta forma, sua existência efetiva-se quando as situações e relações produtivas são experimentadas, não só como interesses e necessidades, mas também como sentimentos, normas e valores. 
Quando as classes sociais são concebidas como um dado espaço constituído e ao mesmo tempo como um espaço de formulações de representações e significados, é preciso que se esteja atento às lutas e movimentos esboçados na vida social. É nesse sentido que a temática dos movimentos sociais torna-se de grande valia na análise da configuração das classes. Sendo estes aqui concebidos como práticas sociais que elaboram a constituição de novos sujeitos. Representam manifestações bem características das sociedades complexas contemporâneas. A diversificação da estrutura social, sua heterogeneidade, as diversas formas de inserção dos sujeitos sociais são, sem dúvida, elementos que compõem a emergência desses movimentos. É muito rica a possibilidade de se captar por meio deles como determinados agrupamentos se colocam no cenário social, fazendo-se representar e reconhecer. É no momento da percepção do fazer representar-se, do se fazer ouvir, da expressão de interesses próprios e da luta coletiva pela defesa desses interesses, que se pode enriquecer a análise das classes sociais.

Para Alain Touraine (1977), o caráter mais novo das classes sociais nas sociedades contemporâneas(que ele denomina pósindustriais), é que, estando menos sustentadas pela transmissão hereditária das posições sociais, por regras institucionais e por aparatos simbólicos, as classes só são realidades observáveis na medida em que figuram, efetivamente, como atores históricos, 
ou seja, em que participam de movimentos sociais, ainda que estes sejam incompletos. Esses movimentos constituem-se, assim, na expressão mais evidente da historicidade. As classes serão reconhecidas a partir da colocação dos atores em movimento. A fundamentação teórica de Touraine tem o mérito de estabelecer o elo de ligação entre o conceito de classes e a noção de movimentos sociais.

Lojkine (1981), por sua vez, caracteriza um movimento social principalmente pela capacidade de um conjunto de agentes das classes dominadas diferenciar-se dos papéis e funções através dos quais a classe (ou fração de classe)dominante garante a subordinação das classes dominadas com relação ao sistema sócio-econômico em vigor. O alcance histórico real de um movimento só pode ser definido pela análise de sua relação com o poder político. Apesar de muitas vezes observando a realidade, não podermos afirmar que os movimentos sociais representam, necessariamente, uma força transformadora, é inegável o seu poder de revigoramento do cenário político. Esses movimentos trazem uma crescente politização da vida social, ampliando a visão do político, que deixa de ser um espaço restrito aos canais representativos instituídos. É importante ainda destacar que na medida em que a estrutura social não é encarada como o único fator determinante das ações de classes, colocando-se como fundamental a forma como os sujeitos sociais vividas poderão estabelecer fronteiras entre as 
classes. Aqui, surge o papel das conjunturas sócio-políticas como fator relevante explicativo, estabelecendo a mediação entre a situação objetiva estrutural e os elementos constitutivos do plano das representações coletivas.

\section{A configuração dos conflitos e as conjunturas sócio-políticas}

Várias análises da constituição dos conflitos nas sociedades contemporâneas, passando pela composição das conjunturas sóciopolíticas, têm apontado para uma diluição da problemática das classes sociais. Uma questão esboça-se: vivenciamos o fim da luta de classes e das classes em si? A ampliação da cidadania em várias sociedades representa a domesticação do poder, a eliminação da luta de classes?

Dahrendorf (1992) como um analista muito empenhado na compreensão dos elementos de composição do conflito social moderno, trabalha várias questões extremamente complexas e polêmicas. Segundo este,

o conflito social moderno refere-se aos direitos de cidadania para todos, num mundo de escolhas ricas e variadas. Ele se fundamenta nas divisões sociais, é levado a cabo na arena política e se desdobra numa multiplicidade de caminhos que dependem de condições culturais e situações históricas específicas.

Segundo, ainda, o seu raciocínio, existem clivagens sociais que dão lugar a conflitos políticos. Mas longe de se tornarem 
progressivamente violentos e destrutivos, esses conflitos forma domesticados por instituições nas quais encontraram expressão constitucional ordeira. Partidos políticos, eleições e parlamento criaram as condições para o conflito sem revolução. Cita Raymond Aron quando este questiona a utilização do termo "luta de classe" e fala de uma saudável rivalidade entre os mais prósperos e os menos, enfatizando que a democracia significa "aceitar conflitos, não a fim de evitálos, mas de impedir que se tornem belicosos". Dahrendorf afirma que

Marx pensou que a sociedade burguesa fosse única no sentido de que, pela primeira vez, a classe oprimida - a classe do futuro-iria abranger a absoluta maioria das pessoas que se organizariam e derrubariam a minoria dominante. Num sentido, foi oposto o que aconteceu. A absoluta maioria das pessoas fundou uma existência razoavelmente confortável(...).

Observamos por essas citações, como o conceito de classes encontra-se totalmente diluído, deixando de ser um ponto de referência fundamental para a compreensão dos conflitos sociais modernos. Fica também claro que o autor tem como referencial as sociedades européias e/ou norte americana, quando apresenta evidências como a existência de uma maioria das pessoas contando com uma vivência "razoavelmente confortável". O que dizer de sociedades como a brasileira e tantas outras da "periferia" do sistema capitalista mundial? Analisando suas conjunturas sócio-políticas verificamos o 
quanto as desigualdades sociais são grandes e como é imprescindível a utilização da categoria das classes sociais na compreensão de sua realidade. O que em hipótese alguma acena para a possibilidade desta utilização fazer-se pertinente apenas nos limites de suas configurações, na medida em que a composição social do "capitalismo periférico" encontra-se articulado a ordenação de seus "pólos centrais". Além do mais, as formas manifestas da desigualdade social nas sociedades "mais desenvolvidas" como o desemprego, discriminações sociais e outras, exige muita cautela com relação ao esvaziamento da noção de classes como categoria teórico explicativa, apesar do "razoável conforto conseguido pela grande maioria da população"- segundo constatação feita por Dahrendorf.

\section{Classes Sociais e Cidadania}

A relação entre a constituição das classes sociais e a luta pela extensão dos direitos de cidadania tem se dado por meio de uma ligação muito íntima. Mas encontramos hoje uma tendência a afrouxar bastante os laços que ligam essas questões. A noção de cidadania aumenta o seu fôlego, com ares de independência e rouba a cena. Não sei se desde os brados da revolução Francesa tivemos um momento em que esta noção estivesse tão em evidência, do discurso dos meios de comunicação de massa ao discurso acadêmico. E aqui é preciso novamente que tenhamos muita cautela, pois a pressão para 
a extensão dos direitos de cidadania teve e tem como pano de fundo os conflitos de classes. Sem querer reduzir todo tipo de conflito a caracterização de conflito de classe, o que é preciso salientar é a abrangência desse fenômeno e a pertinência de destacá-lo na caracterização dos conflitos nas sociedades contemporâneas.

Um exemplo da supervalorização da noção de cidadania como princípio explicativo da composição do conflito social moderno é a proposição de Dahrendorf (1992) de que

uma vez que a esmagadora maioria das pessoas dos países das sociedades da OCDE tornaram-se cidadãos no sentido pleno da palavra, as desigualdades sociais e as diferenças políticas assumiram uma nova compleição. As pessoas não precisam mais juntar forças com outras na mesma posição para lutar por direitos básicos. Elas podem fazer progredir suas chances de vida através do esforço individual, de um lado, e através da representação de grupos de interesses constituídos mas fragmentados, do outro. (...) A nova classe é a classe dos cidadãos, se o paradoxo for permissível, ou, de qualquer modo, a classe da maioria. Um capitulo da história política e social que começou com lutas de classes profundas e potencialmente revolucionárias levou, depois de muitos esforços e sofrimentos, a conflitos mais calmos de antagonismos de classes democráticos ou institucionalizados.

Dahrendorf reconhece o paradoxo colocado, mas parece encará-lo como permissível, o que é lamentável. Como podemos falar em uma "classe de cidadãos"? O aglomerado de cidadãos, ainda que exista majoritariamente, 
abarca grandes clivagens, diferenciações, muitas desigualdades. O que significa um grande agrupamento de cidadãos, se uma das partes se apropria do trabalho da outra? Acredito ainda, que a melhor maneira de responder a essa questão e a muitas outras é procurar delinear a forma como os agrupamentos distinguem-se uns dos outros por meio de sua caracterização econômica, política e sócio-cultual, como vivenciam o mundo e como o representam. Nesse sentido, não encontro melhor aparato analíticoconceitual que o embutido na configuração das classes sociais e as relações travadas por elas. O conceito de classes sociais é o elemento essencial, respaldado por análises conjunturais e despido de ortodoxias e visões messiânicas.

Outra questão colocada na mesa das discussões sobre os conflitos sociais modernos é a possibilidade de realização de um novo contrato social. Sobre que bases ele emergiria? Sobre as bases de uma socialdemocracia? De um novo liberalismo? Socialismo? Melhor não desenterrar o defunto... as alternativas apontadas estão imersas majoritariamente no âmbito de uma democracia capitalista. Essa perspectiva representa sérios limites. Recorro aqui a Przewoski (1989)que salienta o componente do universalismo inerente a ideologia burguesa, onde dentro dos contornos da noção de cidadania, os limites expressam-se na caracterização da mesma como a harmonia básica de interesses dos indivíduos (cidadãos). Na democracia capitalista, as 
massas não agem diretamente em defesa de seus interesses. A representação resulta em uma desmobilização das mesmas. A estrutura do Estado burguês produz pelo menos dois efeitos: separa as lutas econômicas das políticas e impõe uma forma específica à organização de classes em cada uma dessas lutas. Os sindicatos tornam-se organizações separadas dos partidos políticos e a organização de classes assume uma forma representativa.

O estabelecimento de um novo contrato social passa necessariamente pela composição dos vários agrupamentos que integram a sociedade, ainda que todos, ou a maioria esteja abrigada no grande grupo dos cidadãos. São cidadãos que distinguem-se entre si: uns são mais afortunados que outros, uns contam com melhores condições de vida, tem mais prestígio, mais acesso ao saber, ao poder, etc. Então como não procurar caracterizá-los à partir dessas distinções? A caracterização desses agrupamentos como classes sociais representa nesse contexto um exercício bastante salutar. Przewoski com relação a essa questão afirma que as classes são formadas como efeito de lutas; seu processo de formação é perpétuo, elas são continuamente organizadas, desorganizadas e reorganizadas.

A função teórica da análise de classe consiste, pois, em identificar as condições e conseqüências objetivas de lutas concretas. Classe, portanto, é o nome de uma relação, não uma coleção de indivíduos. Os indivíduos ocupam lugares no sistema de produção; os agentes coletivos 